\title{
Penelitian Dan Pengembangan Situs Permukiman Lingkungan Danau Di Jawa Timur: Satu Upaya Menjalin Kemitraan Dalam Pengelolaan Sumberdaya Arkeologi
}

\section{Gunadi Kasnowihardjo}

Keywords: cultural resource management, public archaeology, research publication, utilization, planning

\section{How to Cite:}

Kasnowihardjo, G. (2007). Penelitian Dan Pengembangan Situs Permukiman Lingkungan Danau Di Jawa Timur: Satu Upaya Menjalin Kemitraan Dalam Pengelolaan Sumberdaya Arkeologi. Berkala Arkeologi, 27(2), 1-9. https://doi.org/10.30883/iba.v27i2.948

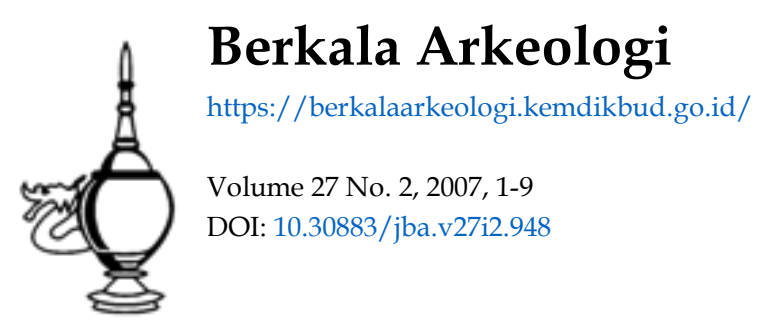

This work is licensed under a Creative Commons Attribution-NonCommercial-ShareAlike 4. 0 International License. 


\title{
PENELITIAN DAN PENGEMBANGAN SITUS PERMUKIMAN LINGKUNGAN DANAU DI JAWA TIMUR: \\ "Satu Upaya Menjalin Kemitraan Dalam Pengelolaan Sumberdaya Arkeologi"
}

\author{
H. Gunadi Kasnowihardjo \\ (Balai Arkeologi Yogyakarta)
}

\section{Pendahuluan}

Evaluasi Hasil Penelitian Arkeologi (EHPA) yang dilaksanakan hampir sekali setiap iahunnya oleh Pusat Penelitian dan Pengembangan Arkeologi beserta jajarannya adalah event akbar yang diikuti oleh para peneliti arkeologi se Indonesia guna mengevaluasi hasil dan kegiatan penelitian selama satu tahun yang telah lewat. Namun apa yang terjadi selama ini menurut hemat saya bukanlah kegiatan evaluasi yang berujung pada upaya perbaikan kinerja penelitian untuk waktu-waktu mendatang, melainkan hanyalah sebuah diskusi ilmiah arkeologi dengan tema-tema yang "bombastis" seiring dengan wacana yang berkembang saat itu. Atas dasar kenyataan tersebut, maka perlu dievaluasi juga model EHPA yang selama ini kita laksanakan.secara rutin dengan beaya yang tidak sedikit.

Seperti tema EHPA yang direncanakan akan diselenggarakan tahun 2007 ini yaitu: "Strategi Membangun Kemitraan Dalam Pengelolaan Sumberdaya Arkeologi", sudah siapkah kita mengevaluasinya? Karena saya yakin diantara Balai-Balai Arkeologi yang tersebar di seluruh Indonesia ini mungkin hingga saat ini masih ada yang mencari-cari kira-kira strategi apa yang harus dilakukan untuk dapat membangun kemitraan tersebut. Oleh karena kegiatan EHPA 2007 batal dilaksanakan, maka artikel yang sedianya akan dipresentasikan pada forum tersebut dengan sedikit perubahan akhirnya kami sampaikan kepada pengelola Berkala Arkeologi untuk diterbitkan.

Sebagaimana terjadinya perubahan nomenklatur Pusat Penelitian Arkeologi Nasional menjadi Pusat Penelitian dan Pengembangan Arkeologi Nasional yang hingga saat ini belum diikuti dengan perubahan nomenklatur Balai- 
Balai Arkeologinya, akan menjadi kendala yang cukup signifikan terutama masalah tugas pokok dan fungsinya yang harus menyesuaikan dengan nomenklatur tersebut. Kata pengembangan dalam nomenklatur yang baru, menurut hemat saya pihak pusat belum mensosialisasikannya dengan gamblang tentang makna kata tersebut terkait dengan tugas pokok dan fungsi yang harus dikerjakan oleh setiap Balai Arkeologi. EHPA tahun 2006 yang tema sentralnya mengangkat tentang nomenklatur Pusat Penelitian dan Pengembangan Arkeologi Nasional, belum dapat merumuskan ketentuan-ketentuan yang tegas tentang nomenklatur tersebut. Karena sampai saat ini belum ada hasil atau rumusan dari EHPA 2006 yang dikirimkan atau disosialisasikan kepada para peneliti arkeologi terutama yang berada di daerah.

Apabila pemahaman dan persepsi diantara para peneliti tentang nomenklatur tersebut telah sepaham, maka langkah berikutnya baru dapat ditentukan dan diselaraskan tentang strategi penelitian yang cocok untuk diterapkan. Hal ini agar hasil dari penelitian arkeologi dapat memenuhi tuntutan akademis, dan bermanfaat pula bagi berbagai pihak baik untuk kepentingan ilmu pengetahuan maupun bagi masyarakat luas. Oleh karena itu, dalam penelitian arkeologi perlu dipikirkan pula langkah-langkah konkrit untuk menjalin kemitraan dengan berbagai pihak yang dapat diajak berkolaborasi. Sehingga dalam penelitian arkeologi yang merupakan bagian dari sistem pengelolaan sumberdaya arkeologi akan tampak kontribusinya dalam mengisi pembangunan bangsa dan Negara ini.

\section{Penelitian dan Pengembangan Situs-situs Permukiman Danau di Kab. Lumajang dan Probolinggo, Jawa Timur}

Penelitian situs-situs permukiman danau di wilayah Kabupaten Lumajang dan Probolinggo telah dilakukan sebanyak dua kali yaitu tahun 2006 dan 2007 oleh Balai Arkeologi Yogyakarta (Goenadi, 2006 dan 2007). Seperti tujuan penelitian yang akan mengungkap tentang permukiman danau di masa lampau, maka objek-objek penelitian dikonsentrasikan pada danaudanau atau Ranu beserta lingkungannya yang ditemukan di kedua kabupaten tersebut. Secara akademis penelitian arkeologi untuk permukiman danau di Jawa Timur pada umumnya dan khususnya di Kabupaten Lumajang dan Probolinggo belum pernah dilakukan. 


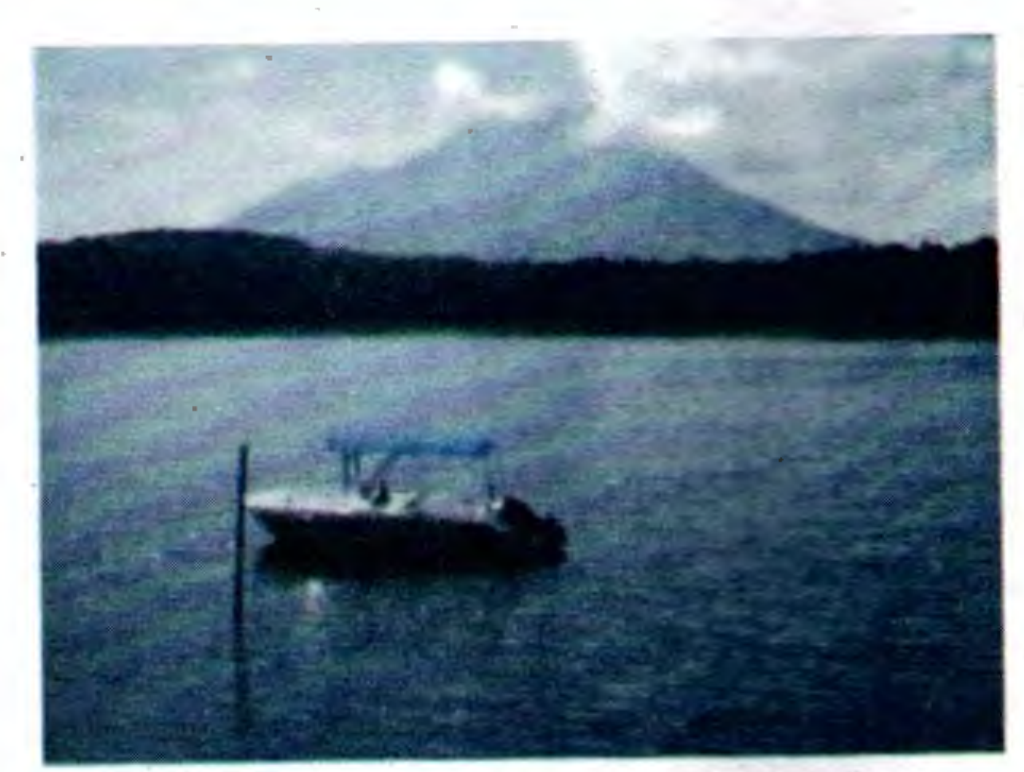

Ranu Klakah. yang hingga sekarang debit airnya masih cukup besar, sehingga banyak dimanfaatkan oleh masyarakat sekitar

Beberapa danau yang telah dilakukan penelitian antara lain Ranu Klakah, Ranu Pakis, Ranu Lading, Ranu Legung, Ranu Yoso, Ranu Bedali, Ranu Wurung dan Ranu Air di Kabupaten Lumajang. Diantara delapan danau tersebut Ranu Klakah yang paling potensial untuk dilakukan penelitian lebih jauh karena memiliki sumberdaya arkéologi yang menunjukkan adanya okupasi manusia yang telah berlangsung cukup lama yaitu sejak masa prasejarah hingga sekarang. Hal ini ditunjukkan dari hasil survey lingkungan Ranu Klakah yang menemukan berbagai tinggalan dari masa prasejarah seperti beliung persegi dan struktur bangunan megalitis. Dari masa hindu-budha ditandai dengan temuan hasil ekskavasi berupa struktur bata yang diperkirakan pondasi sebuah candi. Sedangkan dari masa Islam ditunjukkan dari tinggalan makam tua yang masih menggunakan nisan batu monolit akan tetapi telah berorientasi Utara-Selatan seperti umumnya makam orang Islam (Goenadi, 2007).

Dari papan informasi yang dipasang ditepian danau diketahui bahwa debit air Ranu Klakah maximum sampai saat ini masih mencapai 1,556 M ${ }^{3}$ / detik, ini menunjukkan bahwa danau tersebut cukup potensial dalam menopang kehidupan manusia, sehingga tidak mengherankan apabila kawasan tersebut telah lama dimanfaatkan sebagai permukiman manusia.. Bahkan pada musim kering sekalipun debit minimum Ranu Klakah masih mencapai $0,239 \mathrm{M}^{3} /$ detik, hal ini karena lingkungan danau yang masih didukung oleh lebatnya pepohonan tanaman keras yang masih dijaga kelestariannya oleh masyarakat setempat. Tanpa ada kesadaran dari masyarakat Tegalrandu dan sekitarnya, niscaya Ranu Klakah akan 
mengalami nasib yang sama dengan ranu-ranu lain yang sekarang ini tengah mengalami penyusutan maupun kekeringan seperti yang banyak ditemukan di wilayah Kabupaten Probolinggo.

Penelitian di Kabupaten Probolinggo masih terbatas pada kegiatan survey eksploratif antara melakukan penelitian awal di Ranu Kembar, Ranu Gunung Parang, Ranu Semoka, Ranu Katak, Ranu Gedang, Ranu Segaran, Ranu Agung, Ranu Bethok, Ranu Segaranduwes, Ranu Segaranmerah, dan Ranu Kedunggebek. Penelitian lebih jauh untuk beberapa danau di Kabupaten Probolinggo akan dilakukan atau dilanjutkan pada tahun

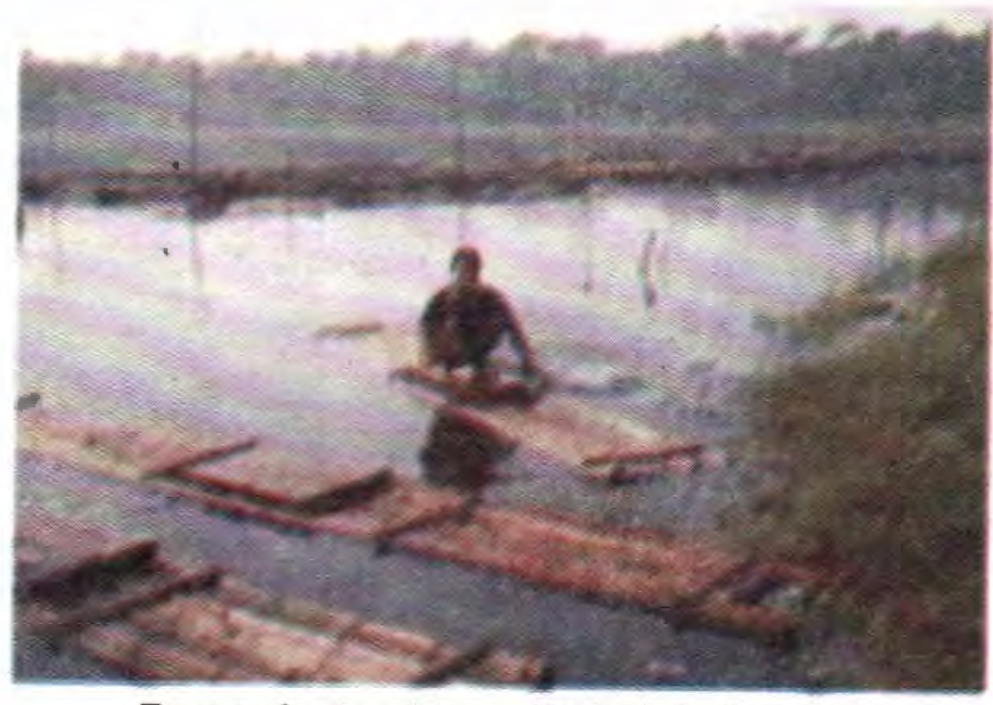

Pemanfaatan Ranu Klakah baik untuk perikanan, mandi dan mencuci

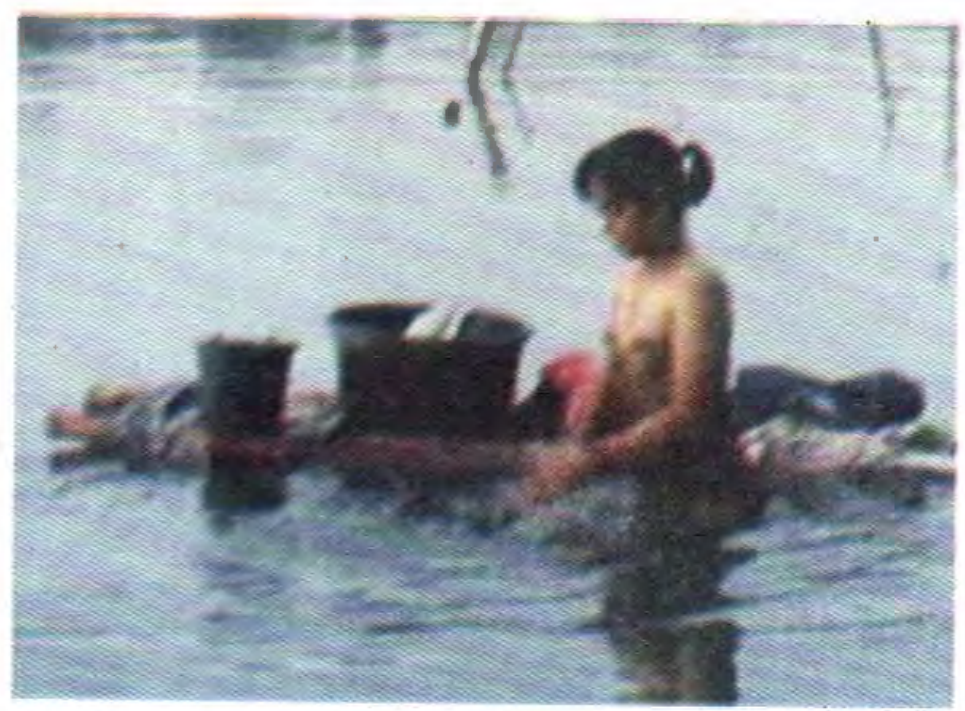

Setiap pagi masyarakat Tegalrandu mandi dan mencuci pakaian mereka di Ranu Klakah

2008 terutama melakukan ekskavasi di lingkungan Ranu Gedang. Pemilihan Ranu Gedang sebagai salah satu sample untuk ekskavasi berdasarkan hasil survey yang menunjukkan bahwa di sekitar areal danau tersebut banyak ditemukan cangkang moluska air tawar dan sebuah batu inti yang dapat dihubungkan dengan kehidupan manusia masa lampau (Goenadi, 2007). 


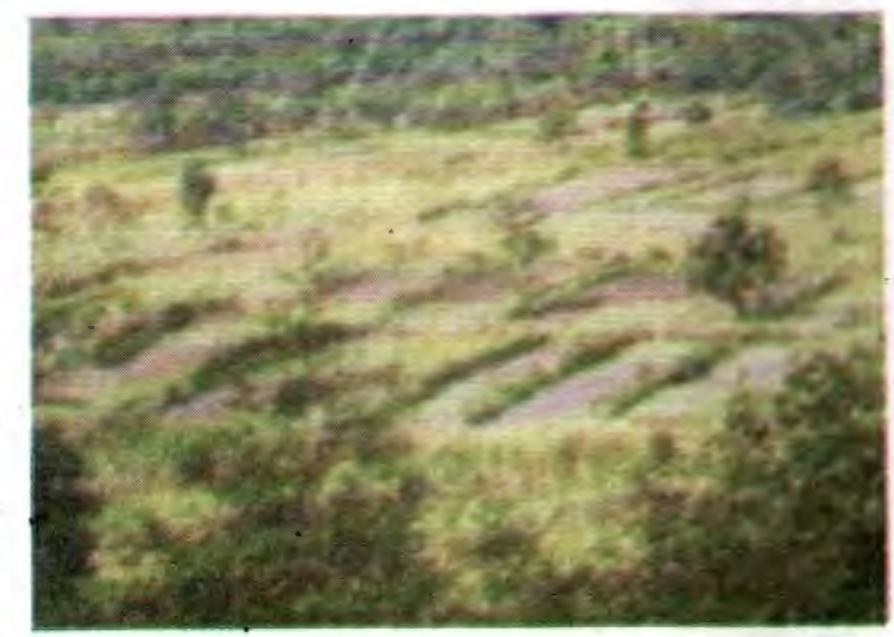

Ranu Katak, salah satu danau di wilayah Kab. Probolinggo yang telah mengering. Dasar ranu dimanaatkan sebagai lahan pertanian.
Manfaat apa yang dapat dirasakan oleh masyarakat luas dari hasil penelitian arkeologi? Pertanyaan ini sangat sulit untuk dicarikan jawabannya, terutama dalam merealisasikan suatu jawaban tersebut.

Dalam kepentingannya yang terkait dengan ilmu pengetahuan jelas, terutama kontribusi kepada disiplin arkeologi. Untuk kepentingan yang terkait dengan masyarakat luas (public), umumnya hasil

penelitian arkeologi akan digulirkan sebagai objek wisata budaya yang dapat dikunjungi baik oleh wisatawan domestik maupun mancanegara. Manfaat seperti tersebut di atas menurut hemat saya sudah merupakan hal yang klasik dan tidak semua sumberdaya arkeologi dapat "berhasil" dijadikan objek wisata budaya, karena hal ini menyangkut berbagai hal seperti sarana dan prasarana yang harus dapat dipenuhi. Oleh karena itu para peneliti arkeologi harus peka terhadap objek-objek yang diteliti dan kasus-kasus serta fonomena-fenomena yang terjadi dan dihadapi di lapangan. Salah satu contoh hasil penelitian permukiman danau di Kabupaten Lumajang dan Probolinggo yaitu fenomena lingkungan yang sangat mencolok antara kedua wilayah tersebut, untuk lingkungan danau-danau di Kabupaten Probolinggo lebih "memprihatinkan" dibandingkan dengan danau-danau yang ditemukan di Kabupaten Lumajang, padahal kedua wilayah tersebut sama-sama terletak di kaki Gunung Lemongan. Dari hasil pengamatan penulis (yang menjadi anggota tim penelitian saat itu) diperkirakan keringnya ketiga buah Ranu Kembar, Ranu Katak, Ranu Semoka, Ranu Bethok, Kedunggebek, dan menyusutnya Ranu Gedang hingga 80 an meter, antara lain karena perilaku masyarakat Probolinggo yang tidak memperhatikan lingkungannya. 
Hal ini berbeda dengan masyarakat Lumajang yang masih memperhatikan keutuhan hutan di wilayah pegunungan Lemongan. Dari salah satu kasus ini maka dapat dilakukan kerjasama antara Arkeologi dan Dinas Lingkungan Hidup maupun Dinas Kehutanan dan Perkebunan pemerintah Kabupaten setempat dengan melibatkan Lembaga Swadaya Masyarakat yang ada. Dengan demikian aspek pengembangan dari hasil penelitian arkeologi tidak "harus" dikaitkan dengan sektor pemanfaatan (misalnya sebagai objek wisata budaya), akan tetapi dapat dikembangkan ke program-program penelitian lain yang lebih komprehensif dengan berkolaborasi bersama pihak-pihak lain.

\section{Penyebarluasan Hasil Penelitian Arkeologi}

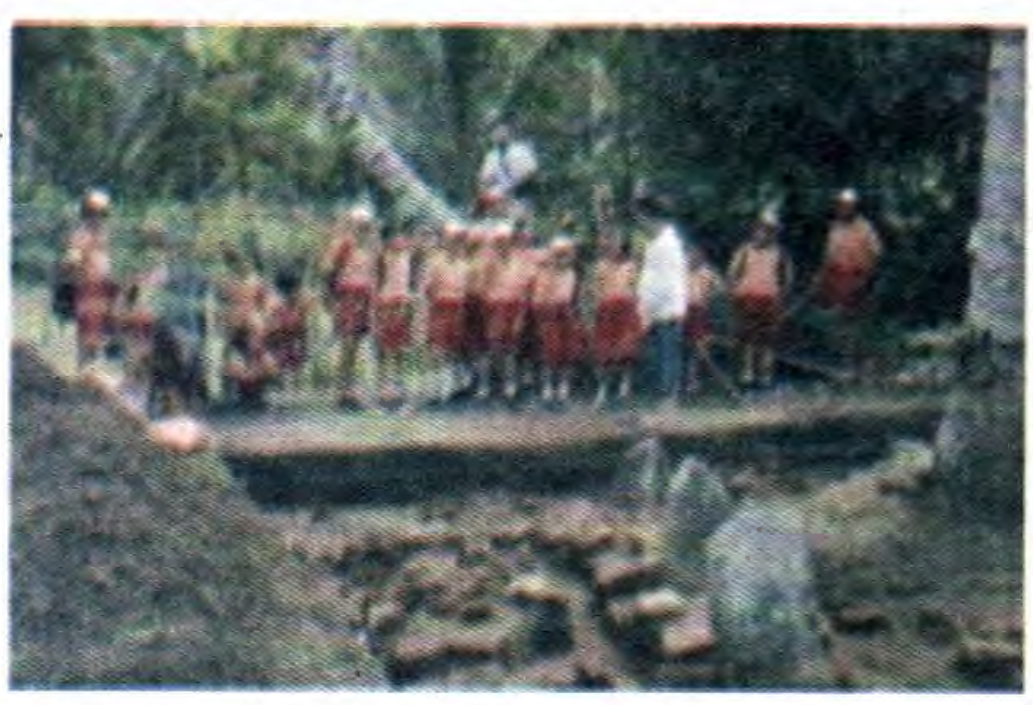

Penyebaran informasi diawali sejak dilakukan penelitian lapangan, terutama kepada para pelajar dan warga setempat

Selain secepatnya harus dilakukan sosialisasi dan publikasi hasil penelitian, terutama kepada pemerintah maupun masyarakat setempat agar secepatnya dapat dipahami dan diambil I angkah-Iangkah pengelolaan yang lebih komprehensif, maka perlu dilaporkan secara khusus. Seperti kasus yang dilakukan di Kabupaten Lumajang, hasil penelitian arkeologi bulan April 2007, sebulan berikutnya dipresentasikan di depan Bupati dan seluruh dinas terkait Kabupaten Lumajang, dan dihadiri pula oleh LSM dan tokoh masyarakat.

Semaksimal mungkin hasil penelitian arkeologi dapat memberikan kontribusi tentang perkembangan sejarah kebudayaan suatu wilayah atau daerah setempat dan dapat dijadikan sebagai muatan lokal bagi pengajaran pada sekolah-sekolah di daerah yang bersangkutan. Bahkan pada saat dilakukan penelitian atau ekskavasi baik masyarakat setempat maupun 
para pelajar dari tingkat prasekolah hingga SLTA disarankan untuk dapat melihat dari dekat bagaimana para ahli arkeologi melakukan kegiatan penelitiannya di lapangan dan apa yang dihasilkannya. Metode dan strategi penelitian harus menyesuaikan dengan paradigma yang berkembang saat ini, baik paradigma dalam bidang akademis, maupun yang bersifat praktis (dalam pengelolaan). Satu contoh setelah dilakukan penggalian (ekskavasi) tidak perlu diurug kembali, baik dengan alasan keamanan sekalipun harus dicari solusi yang tepat agar situs tersebut tetap dapat dilihat dan dipahami baik oleh para ahli maupun masyarakat luas (public).

\section{Kemitraan dalam Pengelolaan Sumberdaya Arkeologi}

Sifat ilmu arkeologi yang multi-disipliner sangat terbuka untuk berkolaborasi dengan berbagai pihak dan sector yang berkepentingan dengan obyek penelitian arkeologi. Kemitraan dalam pengelolaan sumberdaya arkeologi, dapat dibedakan menjadi dua yaitu kemitraan yang bersifat internal dan yang kedua bersifat eksternal. Kemitraan yang bersifat internal seperti diusulkan oleh penulis dalam buku Manajemen Sumberdaya Arkeologi 2 (Gunadi, 2004) tentang konsep three in one yaitu terintegrasikan. yya antara kegiatan penelitian, pelestarian, dan pemanfaatan sumberdaya arkeologi. Konsep ini memang mudah diucapkan akan tetapi sangat sulit untuk dilaksanakan, walaupun bagaimana, kita harus dapat menuju kesana. Kedua, kemitraan yang bersifat eksternal yaitu bentuk kerjasama antara bidang penelitian arkeologi dengan pihak lain (inter disipliner maupun antar lembaga). Satu contoh dalam penelitian permukiman di lingkungan danau di wilayah Kabupaten Lumajang dan Probolinggo, Jawa Timur, kita dapat mengembangkan hasil penelitian tersebut misalnya bekerjasama dengan sector lain seperti lingkungan hidup, kehutanan dan sector lainnya yang terkait untuk merencanakan kegiatan lanjutan yang bersifat kemitraan atau kolaboratif.

Seperti telah dijelaskan sebelumnya bahwa beberapa danau yang ditemukan di dua wilayah kabupaten Lumajang dan Probolinggo saat ini telah mengalami kekeringan yang disebabkan karena hilangnya nilai-nilai kearifan masyarakat terhadap lingkungannya. Untuk mengembalikan agar lingkungan danau dapat kembali seperti dahulu dan bermanfaat bagi kehidupan manusia, perlu dilakukan upaya kerjasama lintas sektoral. 
Dengan demikian hasil penelitian arkeologi juga akan dapat diakses dan bermanfaat bagi kepentingan pihak-pihak lain. Apabila hal ini dapat diwujudkan, maka akan terjalin hubungan kemitraan antar lembaga ataupun antar kepentingan namun dalam koridor yang sama yaitu demi terwujudnya kehidupan manusia yang lebih baik.

\section{Penutup}

Seperti dikatakan oleh Lewis R. Binford dalam bukunya Working at Archaeology (1983 hal. 57) bahwa : For us as archaeologists there is a kind of dual challenge since what the world is likes two forms: one is an orientation toward the archaeological record which is contemporary and with us in here and now. We frequently wish to describe the characteristics of this world. On the other hand, being archaeologists, we wish to talk about the world of the past, we wish to say what that world was like. Dengan demikian, dalam penelitian arkeologi diharapkan dapat mengungkap tidak hanya kehidupan manusia, akan tetapi juga kehidupan alam kita dimasa lampau. Oleh karena itu tidaklah "mengada-ada" apabila kita mampu mengangkat satu kasus yang dapat dikolaborasikan dengan pihak-pihak lain yang terkait.

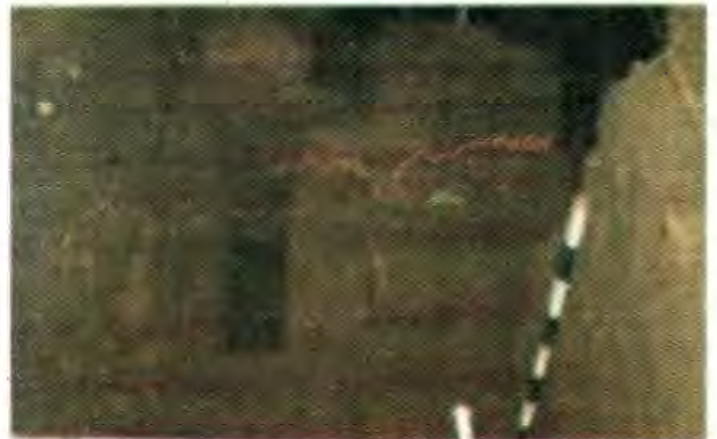

Detail bata temuan dari kotak $\mathrm{H3}$ Sektor Kandang Sapi, tampak ukuran bata sangat besar dibanding bata sekarang

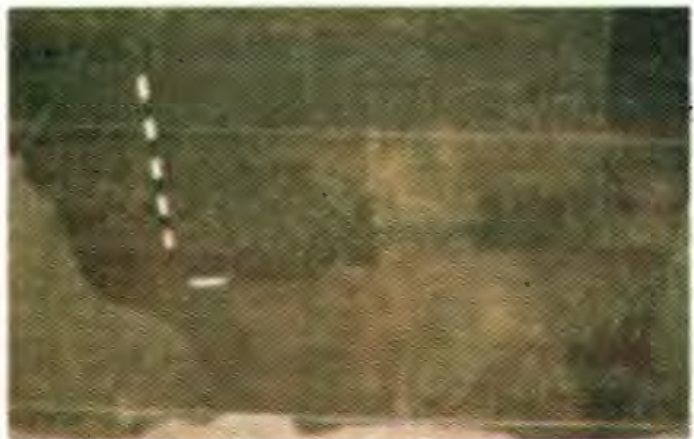

Struktur bata yang diperkirakan sisasisa pondasi candi, hasil ekskavasi sektor Kandang Sapi, Situs Tegalrandu, Klakah. Ditemukan tidak jauh dari batu andeisitis

Dalam menjalin kemitraan arkeologi yang sangat terbuka bagi berbagai disiplin, kesempatan sangat luas, maka tergantung kepada kita sendiri (para arkeolog) mau bermitra dengan siapa? Kejelian para arkeolog dalam menangani hasil penelitiannya sangat menentukan akan dampak yang akan dirasakan oleh masyarakat luas. Hal inilah yang selama ini belum banyak 
terfikirkan oleh sebagian dari para ahli arkeologi kita. Kebanyakan hasil penelitian arkeologi berakhir pada Laporan Penelitian Arkeologi (LPA) ataupun Berita Penelitian Arkeologi (BPA) yang hanya terbatas dibaca oleh para pemerhati arkeologi termasuk mahasiswa jurusan Arkeologi atau sejarah yang memerlukan untuk kepentingan akademis.

Dengan berupaya menjalin kemitraan dan kerjasama dengan berbagai sector dan kepentingan, mudah-mudahan jangkauan, pemikiran dan pertimbangan dalam menentukan model penelitian arkeologi akan dapat lebih meluas dan lebih membumi.

\section{KEPUSTAKAAN}

Binford, Lewis R. 1983. Working at Archaeology, New York: Academic Press, INC.

Clarke, David L. 1978. Analitical Archaeology, New York: Columbia Uniersity Press.

Goenadi NH, 2007. "Situs Permukiman Danau di Kabupaten Lumajang dan Probolinggo", Laporan Penelitian Arkeologi. Yogyakarta : Balai Arkeologi Yogyakarta. belum diterbitkan.

Gunadi, 2001. Manajemen Sumberdaya Arkeologi, Makasar : Lembaga

Penerbitan Universitas Hasanuddin, LEPHAS.

Gunadi, 2004. Manajemen Sumberdaya Arkeologi-2, Banjarmasin: Ikatan Ahli Arkeologi Indonesia Komisariat Daerah Kalimantan.

Rahayu, Suciati. 1992. Proses Terbentuknya Sampah Kerang di Situs Rawa Pening (Studi Ethnoarkeologi). Skripsi. Yogyakarta: Fakultas Sastra. UGM.

Soejono, R.P (ed). 1984. Sejarah Nasional Indonesia I. Jakarta: Balai Pustaka.

Sunarto. 2006. Geomorfologi Danau. Yogyakarta: Fakultas Geografi Universitas Gadjah Mada. 